\title{
Integrated disaster relief logistics: a stepping stone towards viable civil- military networks?
}

Peter Tatham Professor of Humanitarian Logistics, Department of International Business and Asian Studies, Griffith Business School, Australia, and Sebastiaan (Bas) Rietjens Associate Professor Military Management Sciences, Faculty of Military Sciences, Netherlands Defence Academy, The Netherlands

The twenty-first century has seen a significant rise in all forms of disasters and this has resulted in military and humanitarian organisations becoming more frequently engaged in the provision of support to those affected. Achieving an efficient and effective logistic preparation and response is one of the key elements in mitigating the impact of such events, but the establishment of mechanisms to deliver an appropriately integrated civil-military approach remains elusive. Not least because of the high percentage of assistance budgets spent on logistics, this area is considered to represent fertile ground for developing improved processes and understanding. In practice, the demands placed on both civilian and military logisticians are broadly similar, as is the solution space. Speaking a common language and using common concepts, it is argued, therefore, that the logistic profession should be in the vanguard of the development of an improved civil-military interface.

Keywords: civil-military, disaster response, humanitarian logistics, natural disasters

\section{Introduction}

Coordination between civilian and military actors is essential during an emergency response. The increasing number and scale of humanitarian emergencies, in both natural disaster and conflict settings, has led to more situations where military forces and civilian relief agencies are operating in the same environment.

— Sir John Holmes, Emergency Relief Coordinator and United Nations, Under-Secretary General for Humanitarian Affairs, January 2007-August 2010

Since the turn of the millennium, the Centre for Research into the Epidemiology of Disasters (CRED) has reported an annual average of 384 disasters, affecting some 230 million people (CRED, 2012). Many of those affected have suffered rapid-onset disasters, the timing and location of which often are difficult to foresee. However, the outcomes frequently include: damage to and/or destruction of the physical and communications infrastructure; multiple deaths, injuries, and homeless people; disruption to the normal functions of the state; and the presence of the world's media and associated interest from politicians and the public at large. Such a description equally could reflect the circumstances in which a country's armed forces find themselves engaged in military operations and for which they train and prepare in peacetime. Consequently, it is asserted that the armed forces of many countries are not only well prepared to conduct operations in the field of combat, but also in the generically similar conditions that reflect the aftermath of a disaster (Kovács and Tatham, 2009). In particular, many military forces are, as a result of their ability to move quickly with appropriate equipment and trained individuals, ideally suited to offer assistance in support of logistic activities post disaster (Thompson, 2010).

\footnotetext{
${ }^{1}$ http://ochaonline.un.org/OCHAHome/AboutUs/Coordination/CivilMilitaryCoordination/tabid/1274/language/enUS/Default.aspx (accessed on 15 November 2010).
} 
Yet to achieve such mutually congruent objectives, military and civilian actors have to be able to form temporarily viable structures that support or enhance inter-organisational cooperation. Such civil-military structures are, though, extremely complex, with the complexity being induced by, inter alia: the different tasks that need to be performed; differing degrees of time pressure and levels of interdependency between civilian and military co-workers; the non-routine nature of the tasks and their perceived importance; the dynamic context; differing operating cultures, views on leadership, and decision-making processes; and the amount of autonomy available at an operational level (see, for example, Minear, Baarda, and Sommers, 2000; Wheeler and Harmer, 2006; Rietjens et al., 2009). Thus, to be effective, the civil-military network has to remain viable for as long as is necessary to achieve its goals, and this, in turn, suggests that the complexity has to be distributed effectively and efficiently among the network's participants.

With this introduction in mind, the aim of this conceptual paper is to outline the key challenges of the civil-military network as they relate to the logistic aspects of disaster preparation and response, and to discuss the areas in which the development of closer civilmilitary cooperation could be of particular benefit and the means by which this might be achieved. The choice of the logistic sphere is entirely deliberate as it can be seen as a relatively unthreatening environment in which both civilian and military professionals are employing similar processes and procedures. Hence, it represents an area in which mutual cooperation can be fostered, and the resulting insights into the appropriate management of the inherent complexity developed and expanded into the wider civil-military arena.

To achieve this, the next section considers the role of logistics and of the logistician in disaster scenarios. The third section then introduces the Viable Systems Model (VSM) of Stafford Beer $(1985,1990,1995)$ as the theoretical framework that we believe provides an appropriate approach on which to build improved civil-military cooperation both pre and post disaster. The operationalisation of the VSM is illustrated by means of a number of case studies in which military and civilian actors have cooperated in the logistic arena in response to a natural disaster. The final section draws conclusions and offers recommendations for the development and enhancement of civil-military cooperation.

\section{The challenges of humanitarian logistics}

Not only do a significant number of natural disasters devastate the world each year, but the impact of such disasters is rising owing to factors such as burgeoning population levels, increasing urbanisation, and mounting reliance on technology (CRED, 2012). This, in turn, is leading to a greater number of survivors whose welfare becomes the focus of national and international attention, and whose needs are the focus of the humanitarian logistician.

But what is meant by the term 'logistic' in this context? Within the humanitarian community, the following is a frequently quoted definition:

The process of planning, implementing and controlling the efficient, cost-effective flow and storage of goods and materials as well as related information, from the point of origin to the point of consumption for the purpose of meeting the end beneficiary's requirements (Thomas and Mizushima, 2005, p. 60).

Importantly, by viewing 'logistics' in this way, the humanitarian approach is similar to a generic military understanding of the same concept (see, for example, NATO, 1997, para. 103). Furthermore, this challenge is, in practice, closely aligned with the concept of supply network (or chain) management that is a principal component of commercial business 
operations. In this sense, the humanitarian community can be seen to be adopting the 'relabelling' perspective of Larson, Poist, and Halldórsson (2007). But given that the term 'humanitarian logistics' is the one that is generally used within the field, it will be retained in this paper.

In line with the broad definition offered above, Van Wassenhove (2006) has estimated that some 80 per cent of the expenditure of non-governmental organisations (NGOs) pertains to logistics. While others have suggested a slightly lower percentage-Majewski, Navangul, and Heigh (2010), for instance, offer 40-80 per cent - the reality is that the annual cost of humanitarian logistics can be reasonably estimated to be in the range of USD 10-15 billion (Tatham and Pettit, 2010). Self-evidently, this leads to the critical question of how this vast sum can be expended more efficiently and effectively.

In reflecting on this it is important to appreciate that the non-governmental space is populated by a broad range of organisations, including: United Nations (UN) agencies such as the World Food Programme (WFP); the Red Cross movement; national NGOs and international non-governmental organisations (INGOs); global and regional institutions such as the Asian Development Bank and the World Bank; commercial actors such as those that are providing services to UN agencies (TNT Express, for instance); philanthropic bodies such as the Bill and Melinda Gates Foundation; and civil society members such as churches and trade unions. For convenience, therefore, the label 'humanitarian organisations' (HOs) will be used to refer to all such entities except where the context dictates a differentiation.

While this paper argues for improved civil-military logistic cooperation, it must be acknowledged too that there is an associated cost. There is no doubt that, in many instances, the real cost of the use of military personnel and/or equipment exceeds that of a civilian comparator. There are multiple reasons for this, including the use of military equipment that will have been developed (at cost) for an alternative (operational) scenario rather than a benign post-disaster situation. To this must be added the need to recruit, train, and retain personnel with a particular skill set. A further aspect is that, at least to an extent, military procurement practices value 'speed and military necessity over developing sound processes and strengthening host nation institutions' (Paschal, 2012, p. 67), and this leads inexorably to higher costs.

However, one can also contend that, in some circumstances, a military organisation has a clear comparative advantage over its civil counterpart, such as:

- the ability of military organisations to operate in unsafe areas where other organisations either will not, or cannot, operate;

- the short time period in which activities must be completed, with the consequential premium that relates to swift response that can be delivered by military organisations; and

- the absence of actors other than a military that have the capability and/or capacity to undertake the required activities (Rietjens, 2008).

Given these advantages, as well as the fact that military personnel and equipment exist and are available, one can readily understand the desire of a particular country to offer such 'goods-in-kind' rather than a cash donation to the affected country and/or HO community. 
In the light of this reality, it is unsurprising that almost all recent disaster events of any significant size or impact have involved both NGOs and military forces from outside the affected country. Indeed, there have been multiple historic cases of successful cooperation between those HOs and military forces. A classic example is the involvement of the British Army-as part of the North Atlantic Treaty Organization (NATO)'s Kosovo Force response to the humanitarian crisis that developed in Macedonia in 1999-in helping to deal with the massive influx of refugees into the north of that country (Cross, 2011).

In searching for ways to improve the efficiency and/or effectiveness of the overall disaster response, one potentially fruitful line of inquiry appears to be to reflect on the ways in which each of these two communities might be able to work together, each drawing on their particular strengths, in order to achieve the final clause of the Thomas and Mizushima (2005, p. 60) definition: 'for the purpose of meeting the end beneficiary's requirements'.

\section{Theoretical framework}

This paper has adopted the VSM to analyse the operation of the civil-military network because it offers a framework to diagnose and (re)design the distribution of complexity to ensure a network's viability - and in this respect, one sees the management of such complexity as being fundamental to a successful inter-agency approach to logistic preparation and response. In the view of Beer (1995, p. 113), 'viability' refers to a system's ability to maintain a separate existence in its environment. To be viable, systems must have the potential to adapt and realise their objectives. This potential depends on the realisation of five related functions (Beer, 1995; Espejo et al., 1996; Achterbergh and Vriens, 2002). Functions one to three enable the system to realise its goals, whereas functions three to five enable the system to adapt its goals. These functions, and the relationships between them, constitute the template for assessing here the viability of the humanitarian logistics network. In doing so, the study does not attempt either to falsify or to provide support for the VSM as a theoretical model (for this, see, for example, Espejo, 1989); rather, it uses the VSM to open a window on the way in which civil and military organisations deal with the inherent complexity of their network. To achieve this aim, the paper first describes the necessary functions and their relationships, and from this develops a template for evaluating the viability of a civil-military inter-organisational network.

\section{Primary activities}

The first function of a viable system consists of the aggregate of its primary activities. These constitute the organisation's contribution to its environment - the system's raison d'être (Espejo et al., 1996, p. 110). For instance, if the objective of a civil-military network is to receive and accommodate those affected by a disaster, its primary activities might include the provision of food, shelter, and water, basic healthcare, and transportation. However, the existence of a collection of primary activities is insufficient to maintain the viability of the civil-military network. Rather, the primary activities need to be merged into the network as a whole, and for this purpose, the VSM suggests the need for four additional functions: coordination; control; intelligence; and policy.

\section{Coordination}

In a civil-military network, the primary activities may depend on shared resources (including people, stores and equipment, expertise, or the output of other primary activities). This dependency on shared resources makes the primary activities interdependent. In this case the allocation of particular resources (such as drivers and trucks) to a project in the primary activity 'transportation' may require the revision of the allocation of these same resources to a project 
in the primary activity 'providing shelter'. It is the task of coordination to prevent or overcome such problems (Beer, 1995, p. 177).

\section{Control}

Although the primary activities and coordination function are necessary, they are not sufficient for the viability of a civil-military network. To ensure synergy and cohesion among primary activities, the VSM introduces the concept of control. Its task is to translate the identity and mission of the viable system into goals for the primary activities and to monitor their achievement. In this way, 'control' oversees the contribution of the primary activities to the realisation of the identity, mission, and objectives of the viable system as a whole.

\section{Intelligence}

The functions discussed above, while necessary for the realisation of the identity and mission of viable organisations, are still insufficient for organisational viability. Such viability includes adaptation, and to achieve this, a third function is required, which Beer (1995) calls 'intelligence'. It is relevant to note that, in the context of this research, the word intelligence can be seen as reflecting a military perspective, and, as such, is a somewhat loaded term. However, it has been retained within this paper to remain faithful to Beer's original approach, but the concept of intelligence should be taken as reflecting activities such as research, planning, analysis, and change initiation. Consequently, the task of intelligence is to scan the environment of the civil-military network for relevant developments and to initiate adaptation in such a way that the primary activities stay aligned-doing the right thing, instead of doing things right (Espejo et al., 1996).

\section{Policy}

The final function that Beer (1995) introduces is called policy. It has the tasks of coordinating the interaction between control and intelligence, and consolidating the results in a (re)definition of the identity and mission of the civil-military network in such a way that it both fits developments in its environment as well as its own potential for change.

\section{Applying the VSM to civil-military logistic networks}

This section applies the VSM to the practice of civil-military logistic networks through a study of such networks in different settings, including the Southeast Asia tsunami of 2004, the 2005 earthquake and the 2010 flooding in Pakistan, and the Haiti earthquake of 2010. Given the explorative nature of this study, and the complexity and richness of the context, a case-study approach was considered to be the appropriate research strategy (George and Bennet, 2005). Following the method of Yin (2009), a theoretical framework (that is, the VSM) was constructed and then operationalised by means of a case-study protocol.

Data were gathered through an extensive literature study and then, to analyse the information, all of the notes were assembled in matrices, summarising the main findings for each data source, and subequently sorted in respect of their context, content, and process (Miles and Huberman, 1994). To ensure internal validity, the findings were presented to an audience of HO representatives and staff of the first German-Netherlands Corps on 15 February 2011 while they were preparing for a large joint international exercise. This presentation was met with responses of recognition, as well as reactions indicating that important issues had been revealed. Importantly, during this discussion, no new issues of any significance surfaced that had not been covered previously in the presentation. In addition, the issues were discussed informally with a number of practitioners (civilian and military) and, as appropriate, their perspectives incorporated - in practice, most of these viewpoints reflected the emphasis that 
they felt should be attached to a particular issue rather than either offering new considerations or rejecting the basic thesis of the research.

\section{Primary activities}

In broad terms, the logistic response to a disaster can be seen as requiring five primary activities: (i) needs assessment; (ii) immediate (push) response; (iii) procurement of additional stores/equipment; (iv) movement of stores/equipment into the affected area; (v) warehousing and distribution within the affected area-together with associated supporting activities such as information management and donor reporting.

Looking at these activities in slightly more detail, the first pertains to understanding both the numbers and the needs of the affected population. This is not a trivial undertaking, not least because the physical and information infrastructure almost certainly will be severely degraded with concomitant impacts on the capture and dissemination of this information. Furthermore, the needs will be affected by issues such as age and gender, and often with a cultural overlay that leads to differential food and/or clothing requirements (Tatham and Kovács, 2010a). By the same token, reliance on historic data, such as population censuses, can only act as a guide owing to inevitable mass movement away from the affected area.

The achievement of an accurate assessment of needs is primarily the task of local governmental authorities (including national military forces), supported by the $\mathrm{HO}$ community. Currently it is believed that international military personnel are likely to be engaged directly in this process only to a limited extent. That said, there appears to be an increasing possibility that some military technologies, such as unmanned aerial vehicles (UAVs), could be used to good effect as part of the development of an improved understanding of issues such as the material state of transport routes (Tatham, 2009).

Therefore, although a high-level estimate of the likely numbers affected and their needs can be made in order to trigger the 'push' response (including distribution of core items such as blankets, cooking sets, high-energy biscuits, hygiene kits, tents, and water-purification tablets), the danger of relying on a push response is that it may overestimate or underestimate the needs of the population in a particular area. The former represents an inefficient use of resources, whereas the latter leads to an ineffective response. Hence the needs assessment process permits improved targeting of the logistic activities and a move to a 'pull' supply network.

Next comes transporting the relief goods into the affected region, which may be done by air, sea, or land (singly or in combination) and clearly requires a sophisticated level of integration to ensure efficiency and effectiveness. In some cases additional stores and equipment have to be procured locally (primary activity 3 ), but in any event the influx of outside actors often results in demand levels that exceed local supply. Typically, goods are thus stored either in or adjacent to the disaster area (primary activity 4) before the fifth and final activity, distribution, can take place. Again, the means by which this activity is achieved can vary enormously, including the use of helicopters, rugged terrain vehicles, pack animals, and even human transport.

Unfortunately, in many major disaster relief operations, the capacity of national civilian organisations has proved to be insufficient to meet the needs of those affected. As part of the mechanism to fill the resulting gap, many countries provide national military assets and invite/accept international military support across a broad range of functions, including 
communications, coordination, medical support, power distribution, transport, and water/sanitation. For example, the aftermath of the Pakistan earthquake of 2005 saw one of the biggest-ever peacetime NATO operations, which included support in the form of 170 flights transporting 3,500 tons of relief goods (blankets, medical supplies, tents, and similar commodities). In addition, 17 NATO countries deployed more than 1,200 personnel who conducted a variety of logistic missions, including bridge/road repair, provision of water supplies, and the operation of a field hospital and mobile medical facilities (NATO, 2010).

Indeed, research by the Stockholm International Peace Research Institute (SIPRI) indicates that, in the period 2000-07, by far the most common type of military asset provided was air transport (Wiharta et al., 2008), especially during the initial phase of the response when the need was most urgent and in places where access to the affected area was limited. A second category of military assets frequently deployed was medical support in the shape of supplies or of field hospitals, mobile clinics, or hospital ships, such as the USNS Comfort in Haiti. A third important category of military assets that has contributed to disaster response is human resources, particularly personnel skilled in needs assessment, civil-military liaison, and numerous coordination functions. One can see, therefore, that the general trend is for military personnel and equipment to be deployed as 'indirect support' rather than, for example, the provision of last-mile deliveries of supplies to those affected.

\section{Coordination}

The extent of the challenge implicit in achieving a coordinated response between HOs is well understood and reflects, at least in part, the desire of many such organisations to maintain a degree of independence from their colleagues (Telford and Cosgrave, 2007). Given that, in effect, HOs are in competition for donor funding, the desire to demonstrate their superior effectiveness and efficiency can be irresistible (Heaslip, 2010). Furthermore, the sheer numbers of agencies responding to major disasters may overwhelm even the most wellintentioned participants. For instance, Völz (2005) reports that, following the Southeast Asia tsunami of 2004, Banda Aceh (Indonesia) saw 72 coordination meetings per week. By the same token, the OCHA website records more than 900 registered HOs operating in Haiti, a figure that implies the existence of a similar number of supply networks.

Unfortunately, adding foreign military forces to this mixture creates further difficulties and tensions, not least because there is a clear and understandable concern among HOs that the presence of military personnel might jeopardise their freedom to operate in line with their interpretation of the humanitarian principles (Muggah, 2010; Thompson, 2010). However, given that the number of international HOs has been estimated to be in excess of 30,000 (Roberts, 2001), there is a broad spectrum of approaches that spans the space between those organisations characterised by Stoddard (2003) as 'Dunantist', and the more pragmatic 'Wilsonian' entities. By the same token, the military forces of every country are different in terms of their approach to the support for such disasters, their capability, and even their competence (Cross, 2011). Thus, although this paper must, inevitably, discuss the issues relating to civil-military interaction in generalities, it is important to appreciate that this disguises the reality of the many different perspectives and relationships that exist.

Furthermore, it is fully acknowledged that both national and international military forces are, unambiguously, organs of their state and, as such, are directed explicitly or implicitly to act in ways that further the political objectives of that state. The resultant challenge facing the humanitarian respondents reflects both a perceived, and, in some cases, a very real, concern that the military actors will not operate in accordance with the core humanitarian principles of 
humanity, impartiality, and neutrality. Unfortunately, this key conflict of principle is not easily overcome. That said, the extent to which it impacts on the achievement of a coordinated response does, at least to a degree, reflect the particular perspective of the individual humanitarian organisation and the particular military with which it is interacting. Hence, some may be highly uncomfortable operating alongside military personnel, while others may take the view that the needs of those affected outweigh such concerns.

In addition to the different stances HOs have towards the military, there is also, potentially, a significant clash of operating cultures. While military organisations typically adopt a hierarchical model, disaster relief agencies often embody a flatter, action-centred, construct. This dissonance has been explored in a humanitarian context by Dowty and Wallace (2010) who firmly support the contention of Gattorna (2006) in his discussion of the challenges of achieving an integrated supply network. Gattorna (2006, pp. 69-71) observes that:

\begin{abstract}
the potentially damaging impact of mis-aligned culture is a reality that has long been overlooked by the invisibility of culture, and is in stark contrast to the tangible world of hard assets, infrastructure, systems technology and observed behaviour that fills the conscious world. Most people tend to manage what they can see, while either ignoring or remaining oblivious to what they cannot see, touch, or feel.
\end{abstract}

\title{
Control
}

Control aims to establish synergy between the differing primary activities. This means that control translates the goals of the civil-military network into targets for the primary activities and monitors the achievement of these targets. In practice, though, the lack of clarity and the fast-moving nature of a post-disaster response tends to result in objectives and priorities that are (perhaps deliberately) formulated at a high and abstract level and only operationalised to a very limited extent. For instance, the United States Joint Task Force in Haiti was directed 'to conduct humanitarian assistance and disaster relief operations to support United States Government efforts to mitigate near-term human suffering and accelerate relief efforts to facilitate transition to the government of Haiti, the United Nations and USAID [United States Agency for International Development]' (Keen et al., 2010).

By the same token, HOs often suffer a similar challenge in formulating clear goals and targets, usually reflecting the lack of information and the limited time available to initiate the response. For example, the World Disasters Report 2005 describes the situation among relief agencies, local authorities, and tsunami victims in Aceh as an 'information black hole' (IFRC, 2005, p. 80). Owing to significant destruction of the local infrastructure, aid agencies were unable to assess the damage and, as a result, many of them had to operate largely in the dark. As Selanikio (2006, p. 47) pointed out:

they didn't know how many people required medical care; they didn't know how many people were without food, or without shelter; they didn't know how many children were unattended by adults. This made it impossible to efficiently order supplies, or to measure progress: you can't tell how far you have come if you don't know where you started.

Unsurprisingly, therefore, in many disaster areas the design of civil-military networks is essentially improvisational, pragmatic, and ad hoc (Rietjens and Bollen, 2008). Meeting on the ground in the disaster area, personnel from both sets of organisations typically appear to work out solutions and overcome differences to achieve the common good. Hence, the appropriate coordination mechanisms evolve over time in response to the specific circumstances of a particular disaster. That said, initiatives such as the UN cluster system 
have, over time, resulted in increased understanding of the need for staff to be identified who can carry out the key coordinator roles (Steets et al., 2010).

Control of the civil-military network is further influenced by the extent to which authorities of the affected country are capable of managing the disaster relief operation. For instance, Wiharta et al. (2008) found that effectiveness of the use of foreign military assets in disaster relief operations is proportional to the presence of a domestic capacity for disaster management. Thus, in all the cases that they analysed, there was no centralised, functioning disaster management authority, and if 'institutions did exist, they existed on paper only. The lack of internal coordination mechanisms in the affected countries meant that international actors (military and civilian) did not have a structure or system to "plug into"' (Wiharta et al., 2008, p. 39).

\section{Intelligence}

From the perspective of the logistician, and as outlined earlier, achieving a timely assessment of the needs of the affected population is fundamental to building an efficient and effective supply network. Inevitably, in the first instance, much of the logistic response will be on a 'push' basis that reflects the experience of the organisation concerned, and, where possible, is informed by their local staff (Van Wassenhove, Pedraza Martinez, and Stapleton, 2010). Such educated guesses, though, almost certainly will be wrong, at least in part. Recognising that this is a complex area, efforts have been made to develop more standardised approaches to support inter-agency collaboration and coordination - a report by Darcy and Hofmann (2003), for instance, made 29 recommendations for improving the needs assessment process. Unfortunately, there is little evidence of engagement with military forces of countries that potentially may support the affected nation (Wiharta et al., 2008), although there are some indications that this may be changing. For instance, $\operatorname{Vohr}(2011$, p. 80), when discussing the challenges facing the US Marines who were responding to the Haiti earthquake of 2010, concludes that future operations will require a common picture that 'should at [a] minimum capture and display requirements, daily logistics activities, logistics centers, supply routes, medical centers, and engineering projects. It should be unclassified in a humanitarian assistance environment, allowing anyone to access the information with a few mouse clicks or key strokes'.

However, it is not just the assessment of the needs of those affected that can be improved through reasoned dialogue, it is also the actual dissemination of the information that has been captured so painstakingly. An example of the challenge that this poses is reflected in the response to the Pakistan earthquake of 2005 during which the country's military was able to pass on periodical updates by army units deployed throughout the affected areas. These reports became a key source of information on the progress of the relief operation, yet, over time, the quality of the reports began to be seriously questioned, whether it was in respect of the amount of food distributed, the tents delivered, population displacement, or the healthcare situation. When this data was married with other sources, it turned out that the progress reports of subordinate commanders frequently presented a more positive outcome than was justified by the reality on the ground.

The lack of integral situational awareness, and the absence of an adequate overview of priorities and needs, inhibited a coordinated civil-military approach. This is illustrated by the fact that, after the first snowfall in Pakistan, which led to a deterioration in the situation owing to collapsing tents and inaccessibility of villages, emergency meetings were organised to deal with events. Initially, the NATO medical planning group found it difficult to 
understand why the expected arrival of heavy snow and the knowledge of local circumstances had not led to contingency planning at an earlier stage of the relief operation. Contingency meetings had, indeed, been held at an earlier stage, but relevant topics such as further detailed planning for winter conditions were not fully addressed and did not lead to the development of appropriate plans.

Policy

Given the increased use of military forces post disaster, the 'employ/don't employ' decision has been codified by the UN within the 'Oslo Guidelines' (UN OCHA, 2007). Importantly, in the context of this paper, these guidelines emphasise the 'last-resort' principle:

\begin{abstract}
Military and civil defence assets should be seen as a tool complementing existing relief mechanisms in order to provide specific support to specific requirements, in response to the acknowledged 'humanitarian gap' between the disaster needs that the relief community is being asked to satisfy and the resources available to meet them. Therefore, foreign military and civil defence assets should be requested only where there is no comparable civilian alternative and only the use of military or civil defence assets can meet a critical humanitarian need. The military or civil defence asset must therefore be unique in capability and availability (UN OCHA, 2007, p. 4).
\end{abstract}

While, in theory, these guidelines should provide clarity, they contain a clear contradiction in that one of the main advantages inherent in the use of military forces is their ability to deploy swiftly and with appropriate equipment and trained personnel. Such a fast response is potentially lifesaving in the case of many rapid-onset disasters, and yet, if such military forces can only be invited into a country once an assessment of the impact and the indigenous capability has been completed, the window of opportunity may be closed, and lives lost.

It is clear, therefore, that governments (both those affected by the disaster, and those wishing to provide assistance) adopt differing views on the interpretation of the last-resort principle. For instance, as part of research by Wiharta et al. (2008, p. 20), their British adviser suggested that: 'Last resort does not necessarily mean last. We can and will use military assets first if it is considered the best way to save lives [and/or] alleviate suffering'. This variable approach is nowhere more apparent than in the draft guidelines developed by the Asia-Pacific conference on military assistance in disaster relief operations (APC-MADRO), which, although voluntary in nature and not binding on member states, indicates that: 'Requests for Assistance for foreign military support should be made when needs exceed the Affected State's capabilities and no other civilian capacity is available' (UNOCHA, 2010, para. 13). Hence, although the APC-MADRO guidelines are meant to complement the Oslo Guidelines, the form of wording is significantly weaker than the last-resort principle found in the latter. By the same token, the International Federation of Red Cross and Red Crescent Societies (IFRC) has produced a set of guidelines in the form of recommendations to governments on how to prepare their disaster laws and plans to avoid common regulatory problems. These also offer a significantly less prescriptive formula than the Oslo Guidelines, suggesting that: 'Military assets should be deployed for disaster relief or initial recover assistance only ... after comparable civilian alternatives have been considered' (IFRC, 2008, para. 11).

\title{
Discussion
}

The discussion to date has, using the VSM of Stafford Beer (1985, 1990, 1995), focused on responding to the first two aims of this paper, namely the key challenges facing civilian and military logisticians post disaster and the benefits of improved cooperation. This section 
examines the inherent challenges in greater depth and proposes ways in which these might be overcome.

At one level, it might be anticipated that the challenge of achieving cooperation between UN agencies and HOs that operate in line with the principles and standards (and the associated code of conduct) of the Sphere Project (2011) and foreign military forces, which are, by definition, governed by the policies of their government, would be overwhelming. As indicated above, though, the absence of a clear and enduring bipolar relation means that there is room for debate and for developing improved understanding of what is and what is not acceptable in a particular set of circumstances. For instance, in evidence to a United Kingdom parliamentary enquiry relating to events in the Balkans, the then Director General of the Save the Children, Mike Aaronson, observed: 'I think what we all feel is that we have to distinguish between logistical support to a humanitarian operation which is fine, and military co-ordination of a humanitarian military operation, which is not fine' (United Kingdom Parliament, 1999).

On this basis, the question then becomes not one of debating 'if', but rather 'how' civil and military people, processes, and technology can be brought together to best effect to achieve that all important final clause of the Thomas and Mizushima (2005, p. 60) definition: 'for the purpose of meeting the end beneficiary's requirements'. It is further concluded that there is an inexorable move towards greater involvement of military forces in disasters, and that this is increasingly accepted by HOs, although the extent to which this is true will vary across the spectrum of both military and relief organisations. But how can this general trajectory towards greater engagement be supported and developed?

First, it is contended that the prime requirement is the development of the necessary mutual understanding and, importantly, respect between the two communities, and that the activities needed to promote these developments will, unquestionably, be best undertaken prior to, rather than in the heat of, a disaster. Every disaster is, of course, occasion- and circumstancespecific. The strategies and structures for the resulting civil-military networks need, therefore, to reflect the specific and dynamically evolving circumstances (Gourlay, 2000). To date, however, many civil-military networks have depended to a greater or lesser extent on the personalities involved and the qualities that they bring to the table, rather than on planning and standard operating procedures (Rietjens and Bollen, 2008).

However, given that the matter of logistics (as defined in this paper) is central to any disaster response, the development of civil-military engagement has the particular benefit of being able to draw on principles, processes, and techniques that are common to all professionals working in this field. For example, international standards and procedures, such as those relating to waybills, conditions of carriage, and the transport of hazardous goods, are common to $\mathrm{HO}$ and military logisticians, as is understanding of the basic parameters (packing standards, shelf life, volume, weight) that drive decision-making. Indeed, from a theoretical perspective, Gattorna (2010) argues that both the supply networks of military forces and HOs can be characterised as 'fully flexible'-in other words, they are driven by the need to 'do what it takes' to overcome the obstacles in their fast-moving and highly unpredictable environment.

Consequently, the professional basis for mutual cooperation already exists, and, it is suggested that it can be readily developed and built upon. Importantly, however, it is strongly asserted that it is far too late to attempt to meet the potential cultural and 'political' 
challenges after the onset of a disaster. A more appropriate course of action, therefore, is to explore the motivations, capabilities, and approaches of one's potential colleagues during the relative tranquillity of inter-disaster periods. This is likely to be best achieved on a national and/or regional basis, and is exemplified by the current arrangements whereby Irish HOs present to students at the military staff college, and military personnel regularly meet with their Irish HO colleagues (Tatham and Kovács, 2010b).

Second, there needs to be clear and unambiguous acceptance by military forces of the difficulties that their very presence may cause some HOs, especially those whose past interactions with military forces have been less than benign (Thompson, 2010). As a first step, it may well be that simple actions, such as the military avoiding the use of the term 'humanitarian assistance' and instead employing the Oslo Guidelines' terminology of 'international disaster relief assistance' (IDRA), might do much to ensure a more harmonious civil-military relationship - not least because this would acknowledge that the post-disaster actions of military forces may not be accurately described as humanitarian within a strict definition of the term.

Third, the military must acknowledge and accept that the current model in which each country decides on a regime for reimbursement of the costs associated with the use of military assets is at best confusing and, at worst, counter-productive. If, as is argued in this paper, there is, in a logistics context, clear benefit in the employment of a well-trained and well-equipped organisation (that is, elements of a country's military), then this should be accompanied by a transparent and pre-determined charging regime. This would enable prior analysis of the cost-benefit trade-offs and appropriate planning to take place. Such an approach would be greatly supported by the development of international guidelines on how military assets are, or are not, charged to (or offset against) humanitarian budgets.

Fourth, specific actions should be undertaken to explore the mutual benefits of the development of a 'common logistic picture' in which the assets and requirements of participating organisations can be captured in a common format that will promote interorganisational cooperation and coordination. In this regard, one should note that a number of HOs are building on earlier work, such as the Supply Management System (SUMA) of the the Pan American Health Organization (PAHO) and the World Health Organization (WHO), to develop a common supply chain information technology system (Blansjaar and van der Merwe, 2011). Further work is needed to develop the concept and to understand its implications, including the requirement for common feeder processes and systems such as a general catalogue of relief goods - perhaps developed from those already in existence within the IFRC/ICRC (International Committee of the Red Cross) and Oxfam, to name but two major humanitarian organisations. This approach will reduce the potential for individual organisations to resist cooperation on the basis of incompatible systems and processes and offer a means whereby the potential advantages of (technologically-derived) inputs from military sources might be integrated to paint a coherent picture to support coordinated decision-making.

Fifth, and reflecting the well-understood benefits of improved pre-disaster planning, it is suggested that a series of pan-government/HO 'scenario-planning' exercises should be undertaken. These could be used as a basis for reviewing the approaches that would be adopted and the actions taken by each grouping in anticipation of a number of highlikelihood/high-impact events within a specific region. This would lead to the development of improved mutual logistic understanding at the strategic, operational, and tactical level. 
As a corollary of the above scenario-planning approach, it is anticipated that there will be enhanced understanding of the capabilities of country-specific military forces, and, indeed, of mandate-specific HOs. In respect of the former, there is - certainly in relation to those forces from more developed countries - a key set of attributes that can be brought to bear, namely an ability to move equipment, personnel, and stores swiftly, over long distances, and with integral communications and support systems. It is this capability that has the potential to provide life-saving assistance in support of the local government and NGOs/INGOs. Thus, while mandate-specific HOs have invested in on-call capabilities in recent years, they simply do not have the same level of air and ground transport (and associated trained personnel) who are ready, willing, and able to support disaster response activities.

Finally, there needs to be clear recognition among the military forces that, particularly in the light of the sensitivities surrounding their activities (and, in some cases, their very presence), they are likely to be most appropriately engaged in the delivery of equipment, personnel, and stores into a country and internally up to the disaster-affected location rather than in 'lastmile' deliveries. This role may well include engineering activities, such as bridge/road maintenance, repair of water and/or power infrastructure, and possibly the provision of medical support. But the temptation to engage in actual distribution of stores generally should be resisted, however appealing this may be to politicians and/or the media.

\section{Conclusion}

In summary, therefore, and given the inevitable tensions between civil and military agencies, it is argued that developing mutual understanding and trust can be greatly facilitated by the creation of a set of common underpinning processes and procedures. In this respect, the levers of a good logistics response do not differ between humanitarian, military, or, indeed, businesses supply networks. Hence, logisticians are well placed to act as pathfinders in the development of improved and respectful relationships as they belong to an international community that speaks a common professional language, is grounded in a commonality of concepts, and has a common appreciation of the risks to progress and associated blockages. Consequently, there exists an extremely strong basis on which to forge wider mutual trust between organisations that possess understandable differences in approach and outlook-but not in their ultimate motivation.

In short, given its pivotal role in the preparation for, and the response to, a disaster, logistics (in the broadly defined sense of this paper) and the members of the logistics profession across all of the responding agencies and organisations have a highly influential role to play. Improved cooperation would not only pay significant dividends through the development and sharing of best practice and the appropriate integration of people, processes, and technology, but also would help to break down the wider barriers of mutual suspicion that, unquestionably, exist.

\section{Correspondence}

Peter Tatham, Department of International Business and Asian Studies, Griffith Business School, Gold Coast Campus, Parklands Drive, QLD 4222, Australia. Telephone: +61 (0)7 555 28490; fax: +61 (0)7 555 29206; e-mail: p.tatham@griffith.edu.au

\section{References}

Achterbergh, J. and D. Vriens (2002) 'Managing viable knowledge'. Systems Research and Behavioral Science. 19(3). pp. 223-241 
Beer, S. (1985) Diagnosing the System for Organizations. John Wiley and Sons, Chichester. Beer, S. (1990) The Brain of the Firm. Second edition. John Wiley and Sons, Chichester. Beer, S. (1995) The Heart of Enterprise. John Wiley and Sons, Chichester.

Blansjaar, M. and C. van der Merwe (2011) 'The importance of information technology in humanitarian supply chains: opportunities and challenges in the HELIOS project'. In M.G. Christopher and P.H. Tatham (eds.) Humanitarian Logistics: Meeting the Challenge of Preparing for and Responding to Disasters. Kogan Page, London. pp. 47-63.

CRED (Centre for the Epidemiology of Disasters) (2012) 2011: Disasters in Numbers. http://cred.be/sites/default/files/PressConference2011.pdf (last accessed on 5 February 2015).

Cross, T. (2011) 'Disaster agencies and military forces: not such strange bed fellows after all!'. In M.G. Christopher and P.H. Tatham (eds.) Humanitarian Logistics: Meeting the Challenge of Preparing for and Responding to Disasters. Kogan Page, London. pp. 233-248.

Darcy, J. and C.-A. Hofmann (2003) According to Need? Needs Assessment and Decisionmaking in the Humanitarian Sector. HPG Report No. 15. September. http://www.odi.org.uk/resources/download/239.pdf (last accessed on 5 February 2015).

Dowty, R.A. and W.A. Wallace (2010) 'Implications of organizational culture for supply chain disruption and restoration'. International Journal of Production Economics. 126(1). pp. 57-65.

Espejo, R. (1989) 'The VSM revisited'. In R. Espejo and R. Harnden (eds.) The Viable System Model: Interpretations and Applications of Stafford Beer's VSM. John Wiley and Sons, Chichester. pp. 77-100.

Espejo, R., W. Schumann, M. Schwaninger, and U. Bilello (1996) Organizational Transformation and Learning. A Cybernetic Approach to Management. John Wiley and Sons, Chichester.

Gattorna, J. (2006) Living Supply Chains. Financial Times Prentice Hall, London.

Gattorna, J. (2010) Dynamic Supply Chains. Second edition. Pearson Education Limited, Harlow.

George, A.L. and A. Bennet (2005) Case Studies and Theory Development in the Social Sciences. MIT Press, Boston, MA.

Gourlay, C. (2000) 'Partners apart: managing civil-military co-operation in humanitarian interventions'. Disarmament Forum. 3. pp. 33-44.

Heaslip, G. (2010) 'Key funds for NGO administration often neglected in rush to get aid to victims'. The Irish Times. 14 August. http://eprints.maynoothuniversity.ie/2423/ (last accessed on 5 February 2015).

IFRC (International Federation of Red Cross and Red Crescent Societies) (2005) World Disasters Report 2005: Focus on Information in Disasters. http://www.ifrc.org/Global/Publications/disasters/WDR/69001-WDR2005-englishLR.pdf (last accessed on 5 February 2015).

IFRC (2008) 'IDRL guidelines'. http://www.ifrc.org/en/what-we-do/idrl/idrl-guidelines/ (last accessed on 5 February 2015).

Keen, P.K., F.P. Vieira Neto, C.W. Nolan, J.L. Kimmey, and J. Althouse (2010) 'Relationships matter: humanitarian assistance and disaster relief in Haiti'. Military Review. May-June. pp. 2-12

Kovács, G. and P.H. Tatham (2009) 'Responding to disruptions in the supply network: from dormant to action'. Journal of Business Logistics. 30(2). pp. 215-229. 
Larson, P.D., R.F. Poist, and A. Halldórsson (2007) 'Perspectives on logistics vs SCM: a survey of SCM professionals'. Journal of Business Logistics. 28(1). pp. 1-24.

Majewski, B., K.A. Navangul, and I. Heigh (2010) 'A peek into the future of humanitarian logistics: forewarned is forearmed'. Supply Chain Forum: An International Journal. 11(3). http://www.supplychainforum.com/article.cfm?num=22\&art=186\&CFID=9890878\&CFTOKEN=27710946 (last accessed on 17 February 2015).

Miles, M.B. and A.M. Huberman (1994). Qualitative Data Analysis. Second edition. Sage Publications, Thousand Oaks, CA.

Minear, L., T. van Baarda, and M. Sommers (2000) NATO and Humanitarian Action in the Kosovo Crisis. Occasional Paper No. 36. The Thomas J. Watson Jr. Institute for International Studies, Brown University, Providence, RI.

Muggah, R. (2010) 'The effects of stabilisation on humanitarian action in Haiti'. Disasters. 34(3). pp. 444-463.

NATO (North Atlantic Treaty Organisation) (1997) NATO Logistics Handbook. Third edition. http://www.nato.int/docu/logi-en/logist97.htm (last accessed on 5 February 2015).

NATO (2010) 'Pakistan earthquake relief operation'. http://www.nato.int/cps/en/natohq/topics_50070.htm (last accessed on 17 February 2015).

Paschal, M.D. (2012) 'Getting beyond "good enough" in contingency contracting by using public procurement law as a force to fight corruption'. Contracting and Military Operations. 213. pp. 65-139.

Rietjens, S.J.H. (2008) Civil-Military Cooperation in Response to a Complex Emergency: Just Another Drill? Brill Publishers, Leiden.

Rietjens, S.J.H. and M.T.I.B. Bollen (2008) Managing Civil-Military Cooperation: A 24/7 Joint Effort for Stability. Ashgate, Aldershot.

Rietjens, S.J.H., K. Verlaan, T.W. Brocades Zaalberg, and S.J. De Boer (2009) 'Interorganizational communication in civil-military cooperation during complex emergencies: a case study in Afghanistan'. Disasters. 33(3). pp. 412-435.

Roberts, A. (2001) 'NGOs: new gods overseas'. The World in 2001. The Economist Publications, London. p. 73.

Selanikio, J. (2006) 'What we have here is a failure to coordinate'. Liaison. 3(3). pp. 47-49.

Sphere Project (2011) The Sphere Handbook. http://www.sphereproject.org/handbook/ (last accessed on 17 February 2015).

Steets, J. et al. (2010) Cluster Approach Evaluation 2: Synthesis Report. April. http://www.humanitarianinfo.org/iasc/downloadDoc.aspx?docID=5269\&ref=4 (last accessed on 5 February 2015).

Stoddard, A. (2003) 'Humanitarian NGOs: challenges and trends'. In J. Macrae and A. Harmer (eds.) Humanitarian Action and the 'Global War on Terror': A Review of Trends and Issues. HPG Report 14. July. http://www.odi.org.uk/resources/download/240.pdf (last accessed on 5 February 2015).

Tatham, P.H. (2009) 'An initial investigation into the suitability of the use of unmanned aerial vehicle systems (UAVS) to support the emergency assessment process in rapid onset humanitarian disasters'. International Journal of Risk Assessment and Management. 13(1). pp. 60-78.

Tatham, P.H. and G. Kovács (2010a) 'The impact of gender on humanitarian logistics'. International Journal of Mass Emergencies and Disasters. 28(2). pp. 148-169. 
Tatham, P.H. and G. Kovács (2010b) 'The application of "swift trust" to humanitarian logistics'. International Journal of Production Economics. 126(1). pp. 35-45.

Tatham, P.H. and S.J. Pettit (2010) 'Transforming humanitarian logistics: the journey to supply network management'. International Journal of Physical Distribution and Logistics Management. 40(8-9). pp. 609-622.

Telford, J. and J. Cosgrave (2007) 'The international humanitarian system and the 2004 Indian Ocean earthquake and tsunamis'. Disasters. 31(1). pp. 1-28.

Thomas, A.S. and M. Mizushima (2005) 'Logistics training: necessity or luxury?'. Forced Migration Review. 22. pp. 60-61.

Thompson, W.C. (2010) 'Success in Kashmir: a positive trend in civil-military integration during humanitarian assistance operations’. Disasters. 34(1). pp. 1-15.

UN OCHA (United Nations Office for the Coordination of Humanitarian Affairs) (2007)' Oslo Guidelines: Guidelines on the Use of Foreign Military and Civil Defence Assets in Disaster Relief'. Revision 1.1, November 2007.

http://vosocc.unocha.org/Documents/29786_OSLO\%20Guidelines\%20Rev\%201.pdf (last accessed on 5 February 2015).

UN OCHA (2010) Asia-Pacific Regional Guidelines for the Use of Foreign Military Assets in Natural Disaster Response Operations. Draft Version 8.0. 23 November. https://ochanet.unocha.org/p/Documents/APC-

MADRO\%20Draft\%20Guidelines\%20V8.0\%20\%2823\%20November\%202010\%29. pdf (last accessed on 5 February 2015).

United Kingdom Parliament (1999) 'International development minutes of evidence'. Minutes of evidence taken before the International Development Committee, Tuesday 4 May 1999. Question 43.

http://www.publications.parliament.uk/pa/cm199899/cmselect/cmintdev/422/9050401 .htm (last accessed on 5 February 2015).

Van Wassenhove, L.N. (2006) 'Humanitarian aid logistics: supply chain management in high gear'. Journal of the Operational Research Society. 57(5). pp. 475-589.

Van Wassenhove, L.N., A.J. Pedraza Martinez, and O. Stapleton. (2010) 'An analysis of the relief supply chain in the first week after the Haiti earthquake'. http://www.insead.edu/facultyresearch/centres/isic/documents/HaitiReliefSupplyChai n_Final25Jan_.pdf (last accessed on 5 February 2015).

Vohr, J.A. (2011) 'Haiti disaster relief: logistics is the operation'. Military Review. JulyAugust. pp. 76-82.

Völz, C. (2005) 'Humanitarian coordination in Indonesia: an NGO viewpoint'. Forced Migration Review. Special issue. July. pp. 26-27.

http://www.fmreview.org/en/FMRpdfs/Tsunami/full.pdf (last accessed on 5 February 2015).

Wheeler, V. and A. Harmer (eds.) (2006) 'Resetting the rules of engagement: trends and issues in military-humanitarian relations'. HPG Report 21. March. http://www.odi.org/sites/odi.org.uk/files/odi-assets/publications-opinion-files/273.pdf (last accessed on 5 February 2015).

Wiharta, S., H. Ahmad, J.-Y. Haine, J. Löfgren, and T. Randall (2008) The Effectiveness of Foreign Military Assets in Natural Disaster Response. Stockholm International Peace REswearch Institute, Stockholm.

http://books.sipri.org/product_info?c_product_id=358\# (last accessed on 5 February 2015).

Yin, R.K. (2009) Case Study Research: Design and Methods. Fourth edition. Sage Publications, Thousand Oaks. CA. 